\title{
Jaundice in infants and children: causes, diagnosis, and management
}

\author{
YY Chee, Patrick HY Chung, Rosanna MS Wong, Kenneth KY Wong *
}

This article was published on 21 May 2018 at www.hkmj.org.

\section{A B S T R A C T}

Jaundice is caused by an accumulation of bilirubin in the blood. The presentation in infants and children can be indicative of a wide range of conditions, with some self-limiting and others potentially lifethreatening. This article aims to provide a concise review of the common medical and surgical causes in children and discuss their diagnosis and management.

\author{
Hong Kong Med J 2018;24:285-92 \\ DOI: 10.12809/hkmj187245 \\ ${ }^{1}$ YY Chee, MB, BS, FHKAM (Paediatrics) \\ ${ }^{2}$ PHY Chung, MB, BS, FHKAM (Surgery) \\ ${ }^{1}$ RMS Wong, MB, BS, FHKAM (Paediatrics) \\ ${ }^{2}$ KKY Wong *, PhD, FHKAM (Surgery) \\ ${ }^{1}$ Department of Paediatrics and Adolescent Medicine \\ 2 Department of Surgery \\ The University of Hong Kong, Pokfulam, Hong Kong \\ * Corresponding author: kkywong@hku.hk
}

\section{Introduction}

Jaundice is caused by the accumulation of bilirubin in the blood. It can be a result of overproduction of or failure to metabolise and excrete bilirubin. The incidence of infantile jaundice is approximately 1 in 2500 to 5000 live births ${ }^{1,2}$ with a variety of underlying diagnoses ranging from self-limiting breast milk jaundice to aggressive life-threatening diseases such as biliary atresia (BA) and liver failure. Although the clinical features of certain diseases are obvious, some may have more subtle presentations that necessitate a high index of suspicion for diagnosis. In general, the differential diagnoses of jaundice in infancy follow those of adults and can broadly be divided into pre-hepatic, hepatic, and post-hepatic causes. In some cases, specific treatment may not be necessary but more often timely management is required for an optimal outcome. In this article, we highlight several medical and surgical diagnoses of infantile jaundice and a diagnostic strategy based on current evidence.

\section{Medical diseases}

Breast milk jaundice

Breast milk jaundice was first described more than 50 years ago, with benign unconjugated hyperbilirubinaemia associated with breastfeeding. ${ }^{3-5}$ It is the most common cause of prolonged jaundice in an otherwise healthy breastfed infant born at term. It usually presents in the first 2 to 3 weeks of life (incidence has been reported as 34\%), ${ }^{6}$ and can persist for as long as 12 weeks before spontaneous resolution. Total serum bilirubin levels in breast milk jaundice alone do not exceed $200 \mu \mathrm{mol} / \mathrm{L}$. Diagnosis of breast milk jaundice requires the exclusion of other possible pathological causes. Table 1 shows the essential clinical features of breast milk jaundice.
The aetiology of breast milk jaundice is not clear. Animal models suggest that mature breast milk may enhance bilirubin uptake in the gastrointestinal tract, thus increasing enterohepatic circulation and unconjugated bilirubin levels. ${ }^{7,8}$ Higher levels of epidermal growth factor both in the serum and breast milk of affected infants may offer a plausible mechanism for breast milk jaundice in the same way. ${ }^{9}$ Activity of beta-glucuronidase (which deconjugates intestinal bilirubin) that is higher in human milk than formula milk will again increase the serum bilirubin level by increasing enterohepatic circulation. ${ }^{10}$

Severity and duration of breast milk jaundice may be affected by a concurrent neonatal manifestation of Gilbert syndrome which will be discussed later.

Infants with breast milk jaundice require no treatment provided they are clinically well and the total serum bilirubin concentration remains below the recommended phototherapy level. The interruption of breastfeeding is not advised. If total serum bilirubin exceeds $200 \mu \mathrm{mol} / \mathrm{L}$, further investigation is required. In case of a negative workup, the possibility of the additional presence of a mutation of the hepatic enzyme UGT1A1 (uridine diphosphate glucuronosyltransferase 1A1) conjugating bilirubin in the hepatocyte, ie, Gilbert syndrome, should be considered. Follow-up (every 2 weeks) should be offered preferably until a decreasing trend of jaundice becomes evident.

\section{Glucose-6-phosphate dehydrogenase deficiency}

Glucose-6-phosphate dehydrogenase (G-6-PD) is an enzyme found in all cells of the body. Reactive oxygen species (ROS) are continually formed in the body causing tissue oxidation, disruption of lipid membranes, destruction of cell enzyme functions, 


\section{小兒黃㾝病：原因、診斷和治療 \\ 池月兒、鍾浩宇、黃明沁、黃格元}

黃疸病是由於膽紅素在血液中積累造成的。嬰兒和兒童的臨床表現可 能表明不同種類的疾病, 部分可自行復原但其他或會危及生命。本文 簡要綜述黃疸病的醫療及外科病因診斷, 以及討論診斷和治療方案。 alteration of DNA structure, and eventually cell death. Glucose-6-phosphate dehydrogenase plays a major role in neutralising the ROS and offers protection against tissue oxidative damage. Red blood cells are particularly susceptible to oxidative stress so the major effect of G-6-PD deficiency is haematological.

Glucose-6-phosphate dehydrogenase deficiency is a genetic condition with an X-linked recessive inheritance. Males are more likely to be affected. In Hong Kong, there is routine cord blood screening for G-6-PD deficiency and an incidence of around $4.5 \%$ in males and $0.5 \%$ in females. ${ }^{11}$

Glucose-6-phosphate dehydrogenase deficiency-associated neonatal hyperbilirubinaemia can manifest in two forms: severe jaundice resulting from acute haemolysis or gradual onset jaundice. Some G-6-PD-deficient neonates may develop severe haemolysis that results in rapidly rising serum total bilirubin levels, with the potential to develop kernicterus, with or without the identification of a known trigger of haemolysis. ${ }^{12,13}$ In contrast to the

TABLE I. Clinical features of breast milk jaundice

\begin{tabular}{l} 
Jaundice peaks by 2-3 weeks of life and starts to resolve thereafter \\
No clinical suspicion of other pathological causes \\
Normal stool and urine colour \\
Healthy and thriving on physical examination \\
Blood tests show unconjugated hyperbilirubinaemia and normal haemoglobin \\
\hline
\end{tabular}

severe haemolytic jaundice, gradual onset jaundice is less severe and is associated with a slower increase in total serum bilirubin concentration.

Apart from haemolysis (as evidenced by a falling haemoglobin with elevated reticulocyte count), diminished bilirubin clearance plays a role in the pathogenesis of jaundice in G-6-PD deficiency infants. Serum conjugated bilirubin studies indicate diminished bilirubin conjugation in G-6-PDdeficient neonates, ${ }^{14}$ with impaired excretion of conjugated bilirubin into the small intestine in bile.

Prevention of hyperbilirubinaemia and kernicterus in G-6-PD-deficient neonates is possible. Parents of neonates affected should be counselled on the risks of jaundice. They should be advised to avoid triggers of haemolysis (Table $2^{11}$ ). Predischarge measurement of the bilirubin level using transcutaneous bilirubin or serum total bilirubin should be performed followed by earlier and more frequent follow-up. ${ }^{15}$

\section{Gilbert syndrome}

Gilbert syndrome is the most common inherited disorder of bilirubin glucuronidation. The prevalence of Gilbert syndrome has been reported to be $5 \%$ to $10 \%$ in the Caucasian population, ${ }^{16,17}$ with a similar prevalence (3-7\%) in Chinese. ${ }^{18,19}$ Uridine diphosphate glucuronosyltransferase 1A1 is the hepatic enzyme responsible for bilirubin conjugation. Gilbert syndrome results from a mutation in the UGT1A1 gene promotor region. It manifests only in people who are homozygous for the genetic mutation, consistent with an autosomal recessive inheritance. Such mutation may produce structural or functional enzymatic deficiencies, possibly resulting in impaired bilirubin conjugation and hyperbilirubinaemia. Such genetic mutations have been demonstrated in Asian populations..$^{18-20}$

Patients typically present during the adolescent period (with recurrent episodes of jaundice that may be triggered by dehydration, fasting, intercurrent illness, menstruation, etc) when alterations in sex steroid concentrations affect bilirubin metabolism.

TABLE 2. Substances to be avoided in G-6-PD deficient individuals"

1. Chinese herbal medicines (eg, Rhizoma Coptidis [黃連], Flos Lonicerae [金銀花], Flos Chimonanthi Praecocis [臘梅花], Calculus Bovis [牛黃], Margaritas [珍珠末])

2. Western medicines

Antibiotics (eg, nitrofurantoin, nalidixic acid, sulfamethoxazole)

Antimalarials (eg, primaquine)

Antispasmodics (eg, phenazopyridine)

3. Fava or broad beans

4. Mothballs (Naphthalene) and Naphthalene-containing products

Mothers who are breastfeeding their babies with G-6-PD deficiency should consult a doctor before taking any Chinese or western medicine

Abbreviation: G-6-PD = glucose-6-phosphate dehydrogenase 
Nonetheless they may also present with prolonged breast milk jaundice due to concurrent Gilbert syndrome. The diagnosis is made by excluding other causes of unconjugated hyperbilirubinaemia although genetic testing is available. No treatment is necessary. The long-term outcome is similar to that for the general population. Nonetheless the Gilbert genotype is associated with an increased severity and duration of neonatal jaundice. ${ }^{21,22}$

\section{Viral hepatitis}

Among the viral aetiologies in the developing world, hepatitis $\mathrm{A}, \mathrm{B}$, and $\mathrm{E}$ are the most common causes of paediatric acute liver failure (PALF). In the developed world, viruses like herpes simplex virus (HSV) and enterovirus are more commonly identified as the aetiological agent.

\section{Hepatitis viruses}

Hepatitis A virus infection resulting in PALF is uncommon in developed countries $2.5 \%$ in a PALF registry in North America and United Kingdom). ${ }^{23}$ Nonetheless acute hepatitis A virus infection accounts for up to $80 \%$ of PALF cases in developing countries. ${ }^{24}$ Similarly, acute hepatitis B virus (HBV) infection causing PALF is uncommon in the West where $\mathrm{HBV}$ is not endemic. On the contrary, in areas where HBV is endemic, it accounts for up to $46 \%$ of PALF. ${ }^{25}$ Hepatitis E virus infection has rarely been identified as the cause of PALF. Pregnant women have a high risk of fulminant hepatitis associated with hepatitis $\mathrm{E}$ virus infection, with a particularly high risk during the third trimester of pregnancy. The risk of symptomatic hepatitis in the newborn is high if a pregnant woman acquires hepatitis $E$ virus infection during pregnancy.

\section{Infection with viruses other than hepatitis viruses}

Herpes simplex virus should be considered an important and treatable cause of PALF. Herpes simplex virus most commonly affects infants and newborns. In a registry study from North America and the UK, HSV was identified in $25 \%$ of young infants (0-6 months) with PALF. ${ }^{23}$

Other viruses associated with PALF include enterovirus and Epstein-Barr virus. The Enterovirus family (including echovirus, Coxsackie A and B virus) was identified as the aetiological agent of acute liver failure in $2.7 \%$ of young infants ( $0-90$ days of age) in a multi-centre registry in North America and the UK. ${ }^{26}$ Epstein-Barr virus is more frequently implicated in PALF in older children and adolescents.

\section{Chinese herbal medicine-associated hepatotoxicity}

Chinese herbs are being increasingly used in the paediatric population in certain parts of the world and some have been implicated in the development of hepatotoxicity. A recent retrospective review of Chinese herbal medicine-induced liver injury in Beijing, China revealed that Ephedra sinica and Polygonum multiflorum were the major culprit herbs. ${ }^{27}$ These ingredients are found in products such as Gan-mao soft capsules (感冒軟膠), Xiao-erke-chuan-ling (小兒咳喘靈) granules, and Shou-wuyan-shou (首烏延壽丹) tablets that are used to treat upper respiratory tract infection or vitiligo. Jaundice is the most common clinical sign. Median days from herbal ingestion to appearance of presenting symptoms can be up to 30 days. Therefore, it is important to enquire about the use of traditional Chinese medicine in the weeks preceding clinical presentation.

\section{Surgical diseases}

Surgical jaundice commonly refers to obstructive jaundice and consequent impaired biliary drainage. Unlike adults, the causes of obstruction in infants are usually congenital. The differentiation from medical causes can be made by measuring the level of conjugated bilirubin (which will usually be raised in cases of obstructive jaundice) as well as examination of the biliary system by ultrasound scan. Obstructive jaundice is curable by surgery but the magnitude of surgery ranges from minor to ultramajor. The management of individual diagnoses will be discussed below.

\section{Biliary atresia}

The first description in the English language of a condition similar to BA appeared in a textbook written by Dr John Burns from the University of Glasgow in 1817.28 Nonetheless it was more than a century later before the first operation was performed by Dr William Ladd from Boston in an attempt to correct BA. ${ }^{29}$ Unfortunately, his surgery did not improve the outcome of this condition and $\mathrm{BA}$ was at this time regarded as 'the darkest chapter in paediatric surgery? In 1959, Dr Morio Kasai from Japan reported his radical surgery for BA with a higher success rate..$^{30}$ It was only then that BA became a potentially curable condition and the operation that was named after Dr Kasai is now the standard surgical approach for BA.

Biliary atresia is a rare disorder with an incidence that varies widely among populations (1 in 5000 in Asians to 1 in 18000 in Caucasians). In 10\% to $20 \%$ of patients, the disease is associated with other congenital anomalies. ${ }^{31}$ The disease is characterised by inflammatory sclerosing cholangiopathy affecting the entire biliary tract. The bile duct is replaced by fibrous tissue without luminal patency (Fig 1). Its aetiology remains largely unknown and the most 
widely accepted theory is that unknown exogenous factors trigger a series of self-limiting inflammatory events in a genetically predisposed individual during the embryonic or perinatal period. Current evidence suggests that genetics play an important role in the pathogenesis of BA. ${ }^{32}$ A genome-wide association study conducted by a group of scientists in Hong Kong discovered a BA-associated region on chromosome 10q24.2 that could alter the expression of adducin 3 in the liver. ${ }^{33}$ Nonetheless genetic abnormality alone cannot be the sole explanation since BA is not an inherited disease.

Antenatal diagnosis is difficult and only a few small case series have been published. ${ }^{34}$ Affected babies usually present with prolonged jaundice

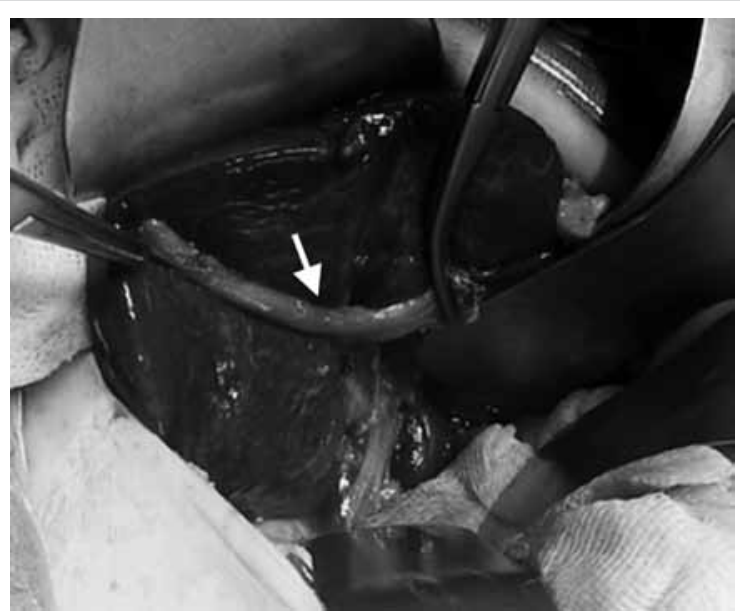

FIG I. An intra-operative photograph showing a 2-monthold boy with biliary atresia, with the entire biliary tract replaced by fibrotic tissue (arrow) without luminal patency

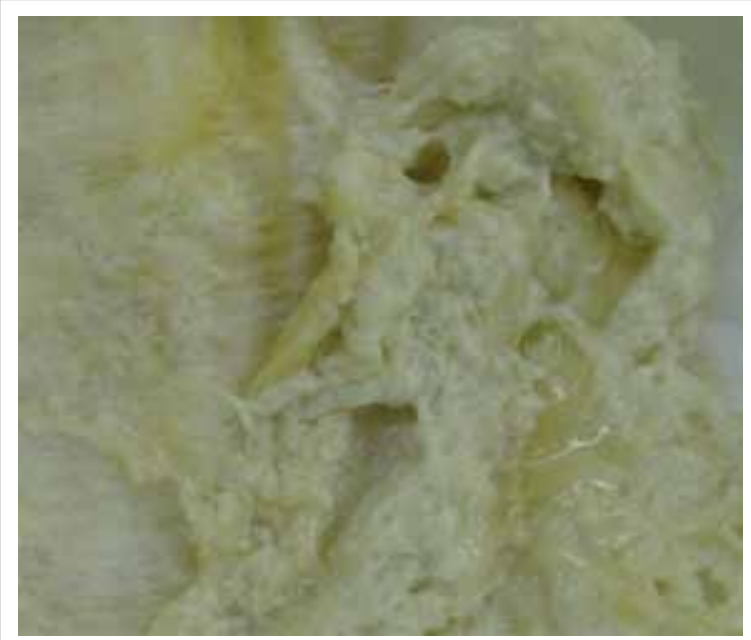

FIG 2. A photograph showing the passage of pale-coloured stool should raise the suspicion of biliary atresia beyond the neonatal period. Due to the absence of bile pigment in the stool, the stool is typically pale in colour (Fig 2). The passage of pale-coloured stool from a young infant should always raise the suspicion of BA. Liver function tests will reveal a cholestatic pattern that may help to differentiate from other causes of infantile jaundice. The gallbladder will be absent or small on ultrasound scan. At a later stage, the liver may demonstrate parenchymal or fibrotic changes. Although radio-isotope scan, such as a techetium-99m ethyl hepatic iminodiacetic acid scan may show impaired biliary excretion, this finding is not confirmatory. The diagnosis of BA should be confirmed by direct visualisation of the fibrotic biliary tract. If necessary, an intra-operative cholangiogram can be performed and is considered normal only if there is passage of contrast up to the intrahepatic ducts as well as down to the duodenum. This diagnostic procedure can now be performed via a laparoscopic approach.

In the majority of cases, the Kasai operation is still regarded as the operation of choice to treat BA and should be carried out in a highly specialised centre. Indeed, the outcome of Kasai operation in the UK has significantly improved following centralisation of all BA cases to three major centres after $1999 .^{35}$ The operation consists of the excision of the fibrous cord at the porta and restoration of biliary drainage by portoenterostomy. Despite an uneventful operation, jaundice clearance can be achieved in only $60 \%$ to $70 \%$ of patients and the 5 -year native liver survival rate is roughly $50 \%$ only. ${ }^{36,37}$ Factors that may improve the outcome including the timing of surgery, experience of the surgeon, surgical approach, and use of adjuvant medications have been studied extensively but a definitive answer is still lacking. Recurrent cholangitis has been found to be associated with a poor outcome and therefore each cholangitic episode should be treated aggressively. ${ }^{38}$ About $30 \%$ to $40 \%$ of post-Kasai patients will eventually develop end-stage liver failure and require liver transplantation as the salvage treatment. ${ }^{39}$

\section{Alagille syndrome}

Alagille syndrome is an autosomal dominant disease with a variable penetrance. The disorder is believed to be caused by a defect in the Notch signalling pathway that is important for normal embryonic development. ${ }^{40}$ This syndrome may present with infantile jaundice resembling BA but it also commonly affects other systems including the cardiovascular, musculoskeletal, and ocular systems. Some patients will have a characteristic facial expression (broad forehead, deep-set eyes and pointed chin). The manifestation in the hepatobiliary system is characterised by the paucity of intrahepatic bile ducts resulting in cholestatic jaundice during infancy. The diagnosis is sometimes confused with 
BA. It is not uncommon for the Kasai operation to be performed on a patient with Alagille syndrome with an invariably poor outcome. Preoperative distinction from $\mathrm{BA}$ is possible by genetic testing for JAG1 mutations but this mutation is also found in some patients with BA, leading to the belief that Alagille syndrome and BA belong to the same spectrum of disease. ${ }^{41}$ At present, the only effective treatment to correct Alagille syndrome is liver transplantation. ${ }^{42}$

\section{Inspissated bile syndrome}

Inspissated bile syndrome describes a condition where the bile duct is obstructed due to the impaction of a thick bile plug or sludge during the neonatal or infantile period. It is sometimes associated with prematurity, cystic fibrosis, or prolonged use of total parenteral nutrition but it can occur without an obvious underlying cause. The use of fluconazole has been reported as a risk factor for developing this disorder. ${ }^{43}$ The affected patient will present with symptoms of obstructive jaundice. Ultrasound examination may occasionally reveal the presence of sludge in the biliary system and dilatation of the bile duct. When the obstruction is mild, the bile plug may dissolve with hydration and high-dose ursodeoxycholic acid. Nonetheless in severe cases with prolonged obstruction, biliary obstruction may lead to liver damage and cirrhosis. Inspection of the gallbladder and the entire biliary tract should be performed to exclude other causes of obstructive jaundice. At the same time, an operative cholangiogram can be carried out to exclude BA by showing the passage of contrast into the intrahepatic ducts as well as small bowel (Fig 3). It also serves a therapeutic purpose by dissolving the bile plug. Some surgeons advocate concomitant cholecystectomy

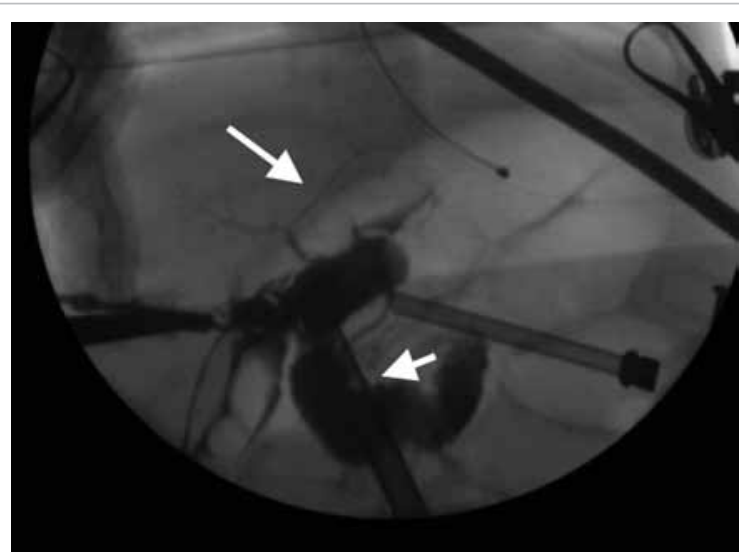

FIG 3. A photograph showing an operative cholangiogram in a 2-month-old boy with hyperbilirubinaemia. Operative cholangiogram is considered normal only if there is passage of contrast into the intrahepatic ducts (top arrow) as well as small bowel (bottom arrow) but it is not always necessary when the diagnosis is straightforward.

\section{Choledochal cyst}

Choledochal cyst is a congenital disorder characterised by cystic dilatation of the intrahepatic and/or extrahepatic bile duct. The estimated incidence is around 1 in 5000 live births and slightly more in Asians. ${ }^{44}$ The diagnosis is usually made in the first few years of life when the patient presents with jaundice or abdominal pain. In recent years, antenatal diagnosis has become more common and more cysts are detected on prenatal scans. Occasionally, the disease can remain asymptomatic until adulthood when it presents with cholangitis. Malignant transformation into cholangiocarcinoma is a rare but possible sequelae of untreated choledochal cyst and thus, surgical excision is recommended..$^{45}$

Choledochal cyst is traditionally classified into five types according to the Todani classification with type I cyst being the most common. ${ }^{46}$ Apart from a stenotic opening at the distal common bile duct causing biliary obstruction, the abnormal union of the pancreatic duct with a long common channel can predispose the reflux of pancreatic juice into the bile duct. Antenatally diagnosed choledochal cyst does not require fetal intervention and asymptomatic cysts after birth can be observed for a while. Nonetheless the observation period should not be long to avoid cholangitis. Earlier surgery has been found to be associated with less liver injury as well as operative complications. ${ }^{47}$ Cholangitic episodes should be treated with potent antibiotics and biliary drainage by either percutaneous or operative means if necessary to avoid progression to life-threatening sepsis.

Complete cyst excision and hepaticojejunostomy is regarded as the standard operative treatment for choledochal cyst. Since the first report of successful laparoscopic surgery in $1995,{ }^{48}$ most centres now perform laparoscopic cyst excision (Fig 4). Previous studies have demonstrated superior outcomes compared with open surgery and it is safe and feasible in young infants. With the advances in laparoscopic techniques among paediatric surgeons, an even more minimally invasive approach by single-incision laparoscopic surgery has been adopted in some centres with satisfactory results. ${ }^{49}$

\section{Diagnostic algorithm}

A diagnostic algorithm for infantile jaundice is summarised in Figure 5. Patients with jaundice beyond the neonatal period require a thorough evaluation for underlying causes. This should always start with recording a careful history of the antenatal and perinatal periods including prenatal 
ultrasonography findings, G-6-PD status, result of the newborn metabolic screen, etc. It is necessary to obtain both the child and mother's medication history to identify any potential hepatotoxic agents. Although breast milk jaundice is a common cause of infantile jaundice, other aetiologies should be considered especially if the infant is not gaining weight, if the total bilirubin level exceeds $200 \mu \mathrm{mol} / \mathrm{L}$, and in the presence of red flag symptoms. The passage

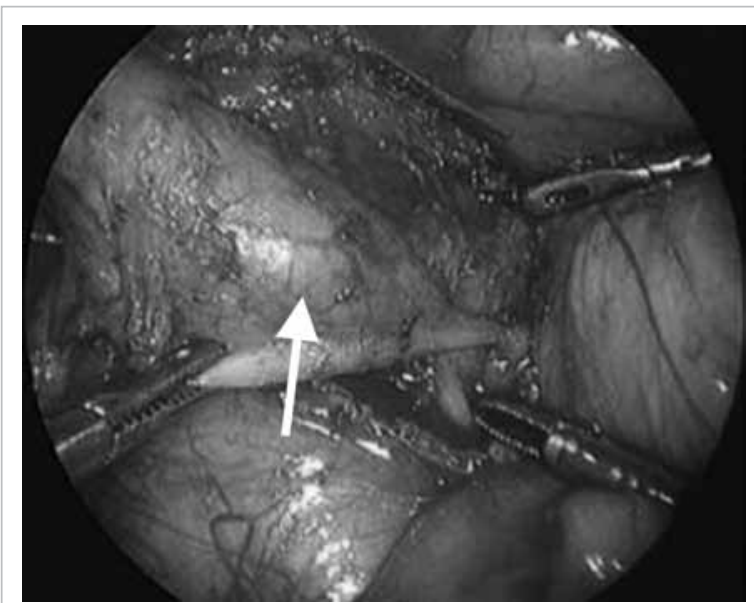

FIG 4. Cystic dilatation of the common bile duct (arrow) in a patient with choledochal cyst of pale stool or tea-coloured urine must not be missed. Physical examination should not be limited to the abdomen and a systematic examination should be carried out to look for associated anomalies. Stool can be saved for inspection of the colour. Blood tests should include a complete blood picture (along with reticulocyte count and peripheral blood smear) to exclude haemolytic diseases. The bilirubin level is measured and it is essential to distinguish between unconjugated and conjugated hyperbilirubinaemia as they suggest different disease entities. An increased level of parenchymal enzyme aspartate aminotransferase/alanine aminotransferase may suggest liver injury due to virus-/drug-induced causes or autoimmune diseases. On the contrary, obstructive causes are suggested by an increased level of ductal enzyme alkaline phosphatase/gamma glutamyl transpeptidase. Serology and antigen of hepatitis viruses can be checked by sending blood samples to a microbiology laboratory. An ultrasound scan can detect the presence of anatomical anomalies in the biliary tract such as BA or choledochal cyst. A radioisotope scan will help to confirm the presence of biliary obstruction but does not always give clues to the underlying diagnosis. Laparoscopic examination of the biliary tract should be arranged when BA cannot be excluded from the above investigations. Nonetheless laparoscopy should also be arranged if cholestasis remains unresolved despite normal imaging to exclude the possibility of inspissated bile

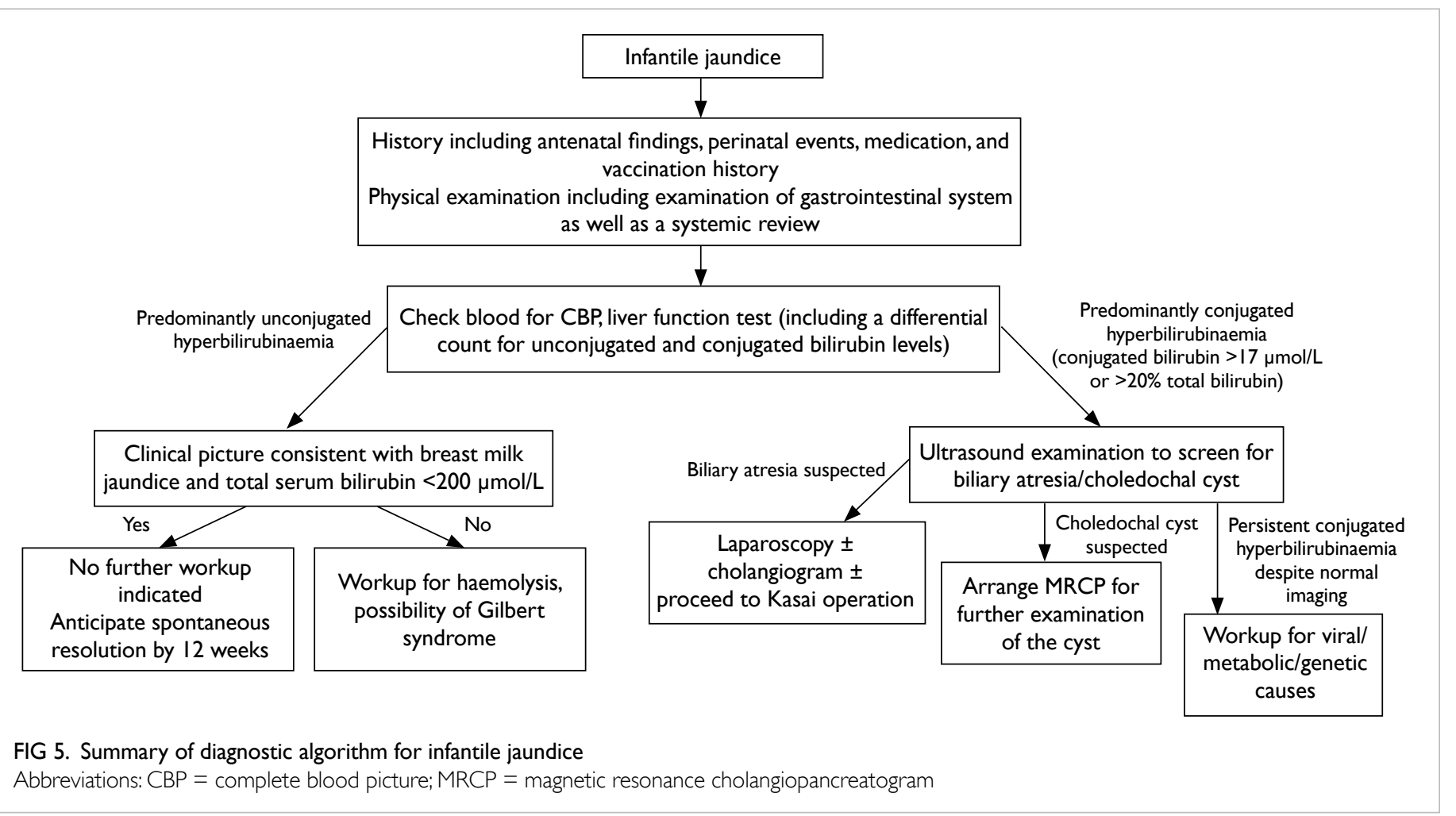


plug syndrome. Intra-operatively, a cholangiogram can be performed by injecting contrast into the gallbladder to confirm the patency of the biliary tract. It also serves the purpose of dissolving any bile plug that may be the cause of obstruction. A liver biopsy can be performed at the conclusion of the procedure to determine the degree of liver injury. The paucity of bile duct in a liver biopsy specimen is suggestive of Alagille syndrome.

\section{Conclusion}

Infantile jaundice is a common but potentially lifethreatening condition. Referral to a specialist is necessary if jaundice persists beyond the neonatal period. The differentiation between medical and surgical causes should be made early on by measuring the blood level of conjugated and unconjugated bilirubin. Laparoscopy should be considered in any patient with persistent cholestatic jaundice to exclude BA that requires early intervention.

\section{Declaration}

As an editor of this journal, KKY Wong was not involved in the peer review process of this article. All other authors have no conflicts of interest to disclose. All authors had full access to the data, contributed to the study, approved the final version for publication, and take responsibility for its accuracy and integrity.

\section{References}

1. Suchy FJ. Neonatal cholestasis. Pediatr Rev 2004;25:38896.

2. Wang JS, Tan N, Dhawan A. Significance of low or normal serum gamma glutamyl transferase level in infants with idiopathic neonatal hepatitis. Eur J Pediatr 2006;165:795801.

3. Gartner LM, Arias IM. Studies of prolonged neonatal jaundice in the breast-fed infant. J Pediatr 1966;68:54-66.

4. Newman AJ, Gross S. Hyperbilirubinemia in breast-fed infants. Pediatrics 1963;32:995-1001.

5. Stiehm ER, Ryan J. Breast-milk jaundice. Report of eight cases and effect of breast feeding on incidence and severity of unexplained hyperbilirubinemia. Am J Dis Child 1965;109:212-6

6. Maisels MJ, Clune S, Coleman K, et al. The natural history of jaundice in predominantly breastfed infants. Pediatrics 2014;134:e340-5.

7. Alonso EM, Whitington PF, Whitington SH, Rivard WA, Given G. Enterohepatic circulation of nonconjugated bilirubin in rats fed with human milk. J Pediatr 1991;118:425-30.

8. Gartner LM, Lee KS, Moscioni AD. Effect of milk feeding on intestinal bilirubin absorption in the rat. J Pediatr 1983;103:464-71.

9. Kumral A, Ozkan H, Duman N, Yesilirmak DC, Islekel H, Ozalp Y. Breast milk jaundice correlates with high levels of epidermal growth factor. Pediatr Res 2009;66:218-21.

10. Gourley GR, Arend RA. beta-Glucuronidase and hyperbilirubinaemia in breast-fed and formula-fed babies. Lancet 1986;1:644-6.
11. Glucose-6-Phosphate Dehydrogenase (G6PD) Deficiency. DH2289, Clinical Genetic Service, Department of Health, Hong Kong. 2016. Available from: http://www.dh.gov. hk/english/main/main_cgs/files/DH2289E\%20G6PD\%20 English.pdf. Accessed 1 Nov 2017.

12. Valaes T. Severe neonatal jaundice associated with glucose6-phosphate dehydrogenase deficiency: pathogenesis and global epidemiology. Acta Paediatr Suppl 1994;394:58-76.

13. Kaplan M, Hammerman C. Severe neonatal hyperbilirubinemia. A potential complication of glucose6-phosphate dehydrogenase deficiency. Clin Perinatol 1998;25:575-90, viii.

14. Kaplan M, Rubaltelli FF, Hammerman C, et al. Conjugated bilirubin in neonates with glucose-6-phosphate dehydrogenase deficiency. J Pediatr 1996;128:695-7.

15. American Academy of Pediatrics Subcommittee on Hyperbilirubinemia. Management of hyperbilirubinemia in the newborn infant 35 or more weeks of gestation. Pediatrics 2004;114:297-316.

16. Owens D, Evans J. Population studies on Gilbert's syndrome. J Med Genet 1975;12:152-6.

17. Sieg A, Arab L, Schlierf G, Stiehl A, Kommerell B. Prevalence of Gilbert's syndrome in Germany. Dtsch Med Wochenschr 1987;112:1206-8.

18. Long J, Zhang S, Fang X, Luo Y, Liu J. Neonatal hyperbilirubinemia and Gly71Arg mutation of UGT1A1 gene: a Chinese case-control study followed by systematic review of existing evidence. Acta Paediatr 2011;100:96671.

19. Chang PF, Lin YC, Liu K, Yeh SJ, Ni YH. Prolonged unconjugated hyperbilirubinemia in breast-fed male infants with a mutation of uridine diphosphate-glucuronosyl transferase. J Pediatr 2009;155:860-3.

20. Maruo $Y$, Morioka $Y$, Fujito $H$, et al. Bilirubin uridine diphosphate-glucuronosyltransferase variation is a genetic basis of breast milk jaundice. J Pediatr 2014;165:36-41.e1.

21. Roy-Chowdhury N, Deocharan B, Bejjanki HR, et al. Presence of the genetic marker for Gilbert syndrome is associated with increased level and duration of neonatal jaundice. Acta Paediatr 2002;91:100-1.

22. Monaghan G, McLellan A, McGeehan A, et al. Gilbert's syndrome is a contributory factor in prolonged unconjugated hyperbilirubinemia of the newborn. J Pediatr 1999;134:441-6.

23. Schwarz KB, Dell Olio D, Lobritto SJ, et al. Analysis of viral testing in nonacetaminophen pediatric acute liver failure. J Pediatr Gastroenterol Nutr 2014;59:616-23.

24. Moreira-Silva SF, Frauches DO, Almeida AL, Mendonça HF, Pereira FE. Acute liver failure in children: observations in Vitória, Espírito Santo State, Brazil. Rev Soc Bras Med Trop 2002;35:483-6.

25. Chen HL, Chang CJ, Kong MS, et al. Pediatric fulminant hepatic failure in endemic areas of hepatitis B infection: 15 years after universal hepatitis B vaccination. Hepatology 2004;39:58-63.

26. Sundaram SS, Alonso EM, Narkewicz MR, et al. Characterization and outcomes of young infants with acute liver failure. J Pediatr 2011;159:813-8.e1.

27. Zhu Y, Li YG, Wang JB, et al. Causes, features, and outcomes of drug-induced liver injury in 69 Children from China. Gut Liver 2015;9:525-33.

28. Burns J. The Principals of Midwifery: Including the Disease of Women and Children. London: Longman; 1817. 
29. Ladd WE. Congenital atresia and stenosis of the bile ducts. JAMA 1928;91:1082-5.

30. Kasai M, Suzuki S. A new operation for "non-correctable" biliary atresia: hepatic portoenterostomy. Shujutsu 1959;(13):733-9.

31. Hartley JL, Davenport M, Kelly DA. Biliary atresia. Lancet 2009;374:1704-13.

32. Lakshminarayanan B, Davenport M. Biliary atresia: a comprehensive review. J Autoimmun 2016;73:1-9.

33. Cheng G, Tang CS, Wong EH, et al. Common genetic variants regulating ADD3 gene expression alter biliary atresia risk. J Hepatol 2013;59:1285-91.

34. Caponcelli E, Knisely AS, Davenport M. Cystic biliary atresia: an etiologic and prognostic subgroup. J Pediatr Surg 2008;43:1619-24.

35. Davenport M, Ong E, Sharif K, et al. Biliary atresia in England and Wales: results of centralization and new benchmark. J Pediatr Surg 2011;46:1689-94.

36. Bijl EJ, Bharwani KD, Houwen RH, de Man RA. The longterm outcome of the Kasai operation in patients with biliary atresia: a systematic review. Neth J Med 2013;71:170-3.

37. Lampela H, Ritvanen A, Kosola S, et al. National centralization of biliary atresia care to an assigned multidisciplinary team provides high-quality outcomes. Scand J Gastroenterol 2012;47:99-107.

38. Chung PH, Wong KK, Tam PK. Predictors for failure after Kasai operation. J Pediatr Surg 2015;50:293-6.

39. Wang P, Xun P, He K, Cai W. Comparison of liver transplantation outcomes in biliary atresia patients with and without prior portoenterostomy: a meta-analysis. Dig Liver Dis 2016;48:347-52.

40. McDaniell R, Warthen DM, Sanchez-Lara PA, et al. NOTCH2 mutations cause Alagille syndrome, a heterogeneous disorder of the notch signaling pathway.
Am J Hum Genet 2006;79:169-73.

41. Dědič T, Jirsa M, Keil R, Rygl M, Šnajdauf J, Kotalová R. Alagille syndrome mimicking biliary atresia in early infancy. PLoS One 2015;10:e0143939.

42. Spinner NB, Leonard LD, Krantz ID. Alagille Syndrome. In: Adam MP, Ardinger HH, Pagon RA, Wallace SE, et al, editors. GeneReviews'. Seattle; 1993.

43. Brownschidle S, Zenali M, Potenta S, Sartorelli K, Sullivan J. Neonatal cholestasis due to biliary sludge-review and report of a case associated with use of Diflucan. Ann Clin Pathol 2014;2:1018.

44. Singham J, Schaeffer D, Yoshida E, Scudamore C. Choledochal cysts: analysis of disease pattern and optimal treatment in adult and paediatric patients. HPB (Oxford) 2007;9:383-7.

45. Madadi-Sanjani O, Wirth TC, Kuebler JF, Petersen C, Ure BM. Choledochal cyst and malignancy: A plea for lifelong follow-up. Eur J Pediatr Surg 2017 Dec 19. Epub ahead of print.

46. Todani T, Watanabe Y, Toki A, Morotomi Y. Classification of congenital biliary cystic disease: special reference to type Ic and IVA cysts with primary ductal stricture. J Hepatobiliary Pancreat Surg 2003;10:340-4.

47. Diao M, Li L, Cheng W. Timing of surgery for prenatally diagnosed asymptomatic choledochal cysts: a prospective randomized study. J Pediatr Surg 2012;47:506-12.

48. Farello GA, Cerofolini A, Rebonato M, Bergamaschi G, Ferrari C, Chiappetta A. Congenital choledochal cyst: video-guided laparoscopic treatment. Surg Laparosc Endosc 1995;5:354-8.

49. Son TN, Liem NT, Hoan VX. Transumbilical laparoendoscopic single-site surgery with conventional instruments for choledochal cyst in children: early results of 86 cases. J Laparoendosc Adv Surg Tech A 2014;24:907-10. 